\title{
An Open-Label Extension Study of the Safety and Efficacy of Risperidone in Children and Adolescents with Autistic Disorder
}

\author{
Justine M. Kent, MD, David Hough, MD, Jaskaran Singh, MD, \\ Keith Karcher, MS, and Gahan Pandina, PhD
}

\begin{abstract}
Objective: The purpose of this study was to evaluate the long-term safety and efficacy of risperidone in treating irritability and related behaviors in children and adolescents with autistic disorders.

Methods: In this 6 month (26 week) open-label extension (OLE) study, patients (5-17 years of age, who completed the previous fixed-dose, 6 week, double-blind [DB] phase) were flexibly dosed with risperidone based on body weight. The maximum allowed dose was $1.25 \mathrm{mg} /$ day for those weighing 20 to $<45 \mathrm{~kg}$, and $1.75 \mathrm{mg} / \mathrm{day}$ for those weighing $\geq 45 \mathrm{~kg}$. The study primarily assessed risperidone's safety; efficacy was assessed as a secondary end-point.

Results: Fifty-six (71\%) out of 79 enrolled patients completed the OLE; the most common discontinuations were for insufficient response (7 [9\%]) or adverse events (AE) (5 [6\%]). The most common ( $\geq 5 \%$ frequency in the total group) AEs were increased appetite $(11 \%[\mathrm{n}=9])$; increased weight and vomiting $(9 \%[\mathrm{n}=7]$ each); sedation, pyrexia, and upper respiratory tract infection $(8 \%[\mathrm{n}=6]$ each); nasopharyngitis $(6 \%[\mathrm{n}=5])$; and somnolence and fatigue $(5 \%[\mathrm{n}=4]$ each). Extrapyramidal AEs were reported in $6(8 \%)$ patients. Increase in mean weight (11-15\%) and body mass index (5-10\%) occurred; one patient discontinued because of weight increase. One potentially prolactin-related AE (irregular menstruation) was reported. The risperidone high-dose group had the greatest mean improvement in sleep visual analog scale (24.6). All groups showed additional improvement in efficacy scale scores during the OLE.

Conclusions: During this OLE, safety findings with risperidone treatment (maximum weight-based dose of $1.25 \mathrm{mg} / \mathrm{day}$ or $1.75 \mathrm{mg} /$ day) were consistent with those observed in the DB phase, and with the current safety information for risperidone in autistic, psychiatric, and behavioral disorders. Patients experienced some additional improvement in irritability and related behaviors.
\end{abstract}

Clinical Trials Registry: This phase-4 study is registered at ClinicalTrials.gov (NCT00576732).

\section{Introduction}

A UTISM, A TYPE OF PERVASIVE DEVELOPMENTAL DISORDER, is characterized by impaired social interaction and communication, along with restricted or stereotyped behaviors (Pandina et al. 2007). Approximately $50-75 \%$ of patients with autism are identified with intellectual disability, in part because of communication deficits; up to $25 \%$ may develop a seizure disorder (Lindgren and Doobay 2011; Miles et al 2010).

Risperidone is a second generation antipsychotic (SGA) agent approved in the United States and $>20$ other countries. In the United States, it is specifically approved for the treatment of irritability and associated symptoms in children and adolescents with autistic disorders, adults and adolescents ( $\geq 13$ years) with schizophrenia, and adults and children or adolescents ( $\geq 10$ years) with bipolar mania (Risperdal ${ }^{\circledR}$ 2011).

Several studies have demonstrated the efficacy of risperidone at flexible doses (ranging from $\sim 0.5$ to $3.5 \mathrm{mg}$ /day) in the treatment of irritability, including severe aggression, rapid mood swings, and tantrums, associated with autistic disorders in children and adolescents (5-16 years of age) (Nicolson et al. 1998; Research Units on Pediatric Psychopharmacology Autism Network 2002; Gagliano et al. 2004; Shea et al. 2004). Long-term safety and tolerability are important considerations for individuals with autistic disorder treated with SGAs, particularly given the established need for ongoing treatment (Williams et al. 2006; Posey et al. 2008). Considering the potential for treatment-emergent adverse events (AEs), including weight gain, metabolic syndrome, tardive dyskinesia

Janssen Research \& Development, LLC, Titusville, New Jersey.

This study was sponsored by Janssen Research \& Development, LLC (previously known as Johnson \& Johnson Pharmaceutical Research \& Development. 
(TD), and others, it is important to determine the lowest effective dose in order to minimize the potential adverse effects, and thus maximize the benefits in treatment management. The efficacy and safety of risperidone at fixed doses (one of which was lower than the recommended dose of $1 \mathrm{mg} /$ day) was previously evaluated in a 6 week double-blind (DB) phase in autistic children and adolescents (Kent et al. 2013). Here, we present the safety findings from the 6 month (26 week) open-label extension (OLE) to this DB study.

\section{Methods \\ Study population}

Patients of either sex, ages 5-17 years, inclusive, weighing $\geq 20 \mathrm{~kg}$, diagnosed with autistic disorder (Diagnostic and Statistical Manual of Mental Disorders, 4th ed. [DSM-IV] and Autism Diagnostic Interview - Revised [ADI-R]) were enrolled in the DB phase of this study. These patients had an Aberrant Behavior Checklist-Irritability (ABC-I) subscale score of $\geq 18$ and a Clinical Global ImpressionsSeverity (CGI-S) scale score of $\geq 4$ at screening and baseline; and had a mental age of at least 18 months (Leiter International Performance Scale - Revised or another standardized, individualized, test of intelligence) measured and documented at any time before or at screening (American Psychiatric Association 1994). The detailed eligibility criteria for the DB phase are published separately (Kent et al. 2013).

Patients were eligible for entry into the OLE if they had either completed the 6 week DB phase or had discontinued from the DB phase after at least 3 weeks for reasons other than tolerability, (provided $\leq 4$ weeks had elapsed since completion or discontinuation), and, in the investigator's judgment, needed risperidone treatment. The patients' randomization group in the DB phase remained blinded to both site and sponsor staff until the completion of the OLE study. Patients who were pregnant or breast-feeding were excluded.

This study was conducted in accordance with the ethical principles that have their origin in the Declaration of Helsinki, in accordance with the International Conference on Harmonisation (ICH) Good Clinical Practice guidelines, applicable regulatory requirements, and in compliance with the protocol. All parents (or their legally acceptable representatives) of the children and adolescents provided written informed consent and children and adolescents provided assent after a discussion using age-appropriate language about the study, according to local regulations.

\section{Study design}

This was a 26 week flexible-dose OLE to a 6 week fixed-dose, DB, randomized, placebo-controlled, multicenter study (Fig. 1). This study was conducted in the United States from December 3, 2007 to March 9, 2010. During the OLE, patients received a flexibledose regimen of risperidone within a given weight-based dose range, as will be described. The individual dose was adjusted to acceptable tolerability and effectiveness. OLE baseline visit assessment data were collected for all patients entering OLE. The baseline visit for the OLE could be on the same day as the end-point visit of the DB phase (week 6 or early withdrawal). If the day of OLE baseline visit was within 14 days of the DB end-point visit, then the DB end-point assessments were not repeated at the OLE baseline visit. The OLE safety and efficacy evaluations were completed during the visits at weeks 0 (baseline), 1, 2, 4, 13, and 26, or upon early withdrawal from the OLE phase.

\section{Study medication}

Risperidone was provided as oral solution $(0.1 \mathrm{mg} / \mathrm{mL})$ and as tablets in blister wallets of 10 tablets each (strengths of $0.25,0.5$, and $1 \mathrm{mg}$ ).

\section{Dosage and administration}

Risperidone was flexibly dosed during the OLE, and titrated by the investigator according to tolerability and efficacy. Prior to the OLE, in the DB phase, risperidone was administered at two dose levels: low dose (range $0.125 \mathrm{mg} /$ day or $0.175 \mathrm{mg} /$ day, based on weight) and high dose $(1.25 \mathrm{mg} /$ day or $1.75 \mathrm{mg} / \mathrm{day}$, based on weight). In the OLE, risperidone was administered as oral solution $(0.1 \mathrm{mg} / \mathrm{mL})$ for the first 3 days and as tablets from day 4 onwards. On day 1 , patients started with a $0.125 \mathrm{mg} /$ day (patients weighing < $45 \mathrm{~kg}$ : $1.25 \mathrm{~mL}$ of $0.1 \mathrm{mg} / \mathrm{mL}$ oral solution) or $0.175 \mathrm{mg} /$ day (patients weighing $\geq 45 \mathrm{~kg} ; 1.75 \mathrm{~mL}$ of $0.1 \mathrm{mg} / \mathrm{mL}$ oral solution) dose of risperidone. On day 4 , the dose was increased to $0.25 \mathrm{mg}$ for all patients, and after day 14, increases in increments of 0.25 or $0.5 \mathrm{mg}$ every 2 weeks were allowed. Dose adjustment (upward or downward) was allowed as indicated by the patient's clinical condition. The maximum allowed dose was $1.25 \mathrm{mg} /$ day (patients weighting $<45 \mathrm{~kg}$ ) or $1.75 \mathrm{mg} /$ day (patients weighing $\geq 45 \mathrm{~kg}$ ). Risperidone was administered once daily in the morning or, if somnolence occurred, in the evening.

\section{Concomitant medications}

Anticholinergic medications and antihistamines for treatment of emergent extrapyramidal symptoms (EPS) were allowed at the lowest effective dose and for the shortest possible duration. For patients with stable seizure disorders (i.e., for at least 6 months), anticonvulsant medications were allowed for those who were stable on a particular dose for at least 4 weeks before study start. Patients who had been stable on hypnotic or sedative medications at a constant dose for at least 30 days before the study started were allowed to continue with these medications. No sedative or hypnotic medications were allowed during the 8 hours preceding any behavioral assessment. Patients had to be medication-free for all other psychotropic medications for at least 1 week (except 4 weeks for fluoxetine or 8 weeks for depot medications) before the baseline visit.

\section{Safety assessments}

Safety assessments included evaluation of AEs (only those AEs that had a new onset in OLE phase of the study are reported); EPS rating scales (Abnormal Involuntary Movement Scale [Guy 1976.], Barnes Akathisia Rating Scale [Barnes 1989], and Simpson-Angus Rating Scale [Simpson and Angus 1970]) scores; Night Time Sleep Quality and Daytime Drowsiness Visual Analog Scale (VAS) scores (scale of 0-100) (Harvey et al. 2005); Tanner staging (Marshall and Tanner 1969, 1970) for sexual maturation; clinical laboratory parameters; measurement of body weight, height, and vital signs, 12-lead electrocardiogram; and physical examinations.

Change from DB baseline (before randomization) to OLE endpoint was measured for the following clinical laboratory parameters: glucose, lipids, insulin, growth hormone-related factors, and prolactin. Insulin resistance (homeostatic model assessment of insulin resistance [HOMA-IR]) was calculated using the formula: glucose $(\mathrm{mmol} / \mathrm{L}) \times$ insulin $(\mu \mathrm{U} / \mathrm{mL}) / 22.5$ (Wallace et al. 2004). HOMA-IR values $>3$ were considered "markedly abnormal." Insulin-like growth factor (IGF-1) and IGF-binding protein (IGF-BP-3) were 


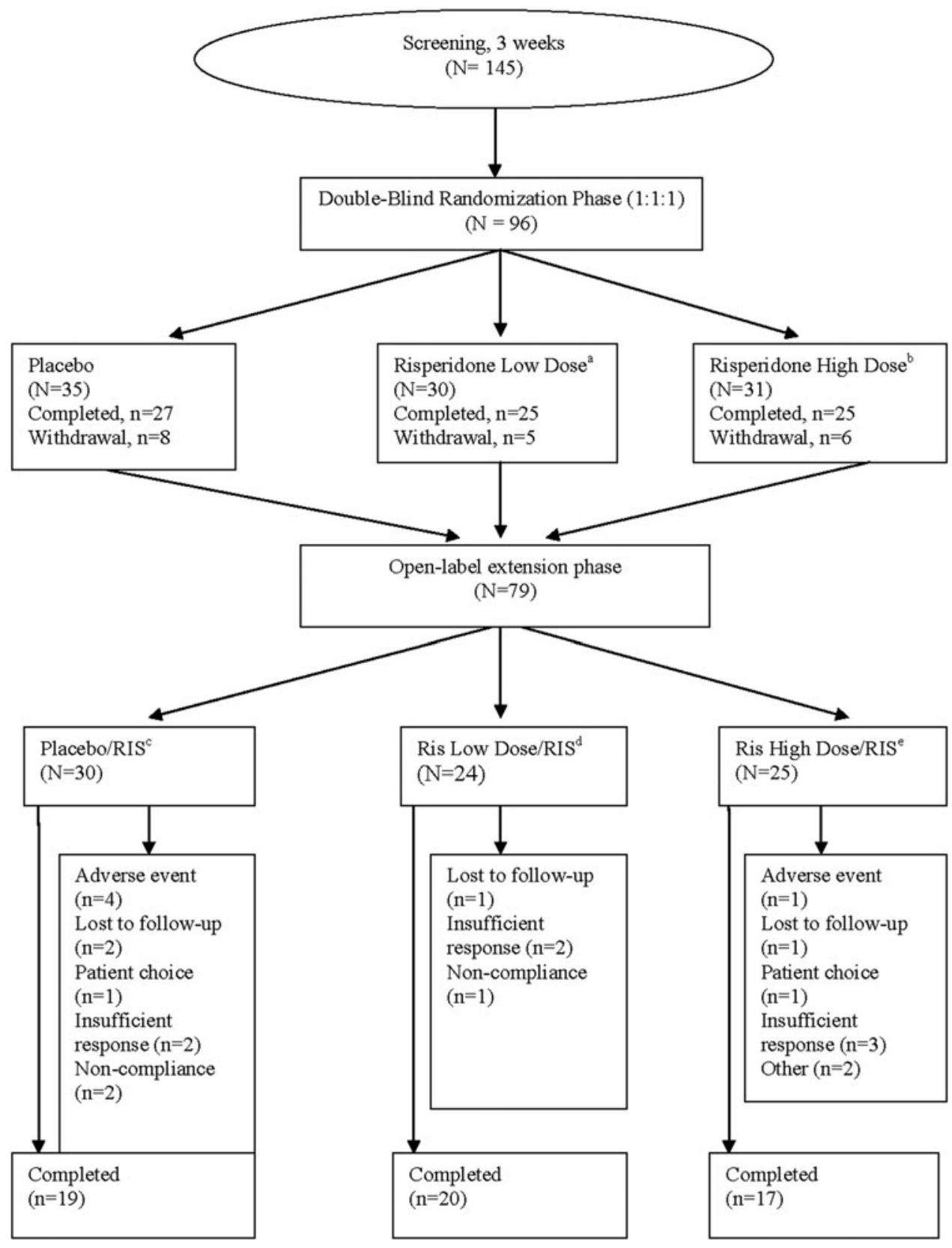

FIG. 1. Study design and patient disposition. ${ }^{\mathrm{a}} 0.125 \mathrm{mg} / \mathrm{day}$ (patients weighing $20 \mathrm{~kg}$ to $<45 \mathrm{~kg}$ ). ${ }^{\mathrm{b}} 0.175 \mathrm{mg} / \mathrm{day}$ (patients weighing $\geq 45 \mathrm{~kg}$ ). ${ }^{\mathrm{c}}$ Patients randomly assigned to placebo during double-blind (DB) phase who continued into open-label extension (OLE) and received risperidone. ${ }^{\mathrm{d}}$ Patients randomly assigned to risperidone low dose in DB phase and receiving risperidone (as per weight class) in OLE phase. ${ }^{e}$ Patients randomly assigned to risperidone high dose in DB phase and receiving risperidone (as per weight class) in OLE phase.

initially measured using an enzyme immunoassay (EIA) method. As the EIA assay method did not have pediatric reference ranges available, a new assay method, Immulite ${ }^{\circledR}$ (Siemens Medical Solutions Diagnostics, NJ), which had pediatric reference ranges as well as means and standard deviations (SDs) from a normal population, was introduced during the study (Elmlinger et al. 2004). There was a strong correlation between the two assays in this study (correlation coefficient $=0.96$ ), hence, results were summarized only for the EIA assay, for which results were available for all patients. The Immulite normal population means and SDs were transformed based on a linear regression of EIA values on Immulite values from the current study. These derived normal population means and SDs were then used to derive SD scores (SDS) for EIA values as: $\left[\log (\mathrm{IGF}-1)-\right.$ mean $\left._{\text {log-scale }}\right] / \mathrm{SD}_{\text {log-scale }}$.

\section{Efficacy assessments}

The mean change from $\mathrm{DB}$ baseline (before randomization) to OLE end-point in the scores for the ABC-I subscale; other ABC subscales (Lethargy or Social Withdrawal, Stereotypic Behavior, Hyperactivity or Noncompliance, and Inappropriate Speech); CGIS; and Children's Yale-Brown Obsessive Compulsive Scale-Pervasive Developmental Disorder (CY-BOCS-PDD) (Scahill et al. 2006) compulsion subscale were evaluated. 
Additionally, response rate at each visit (response was defined as at least $25 \%$ improvement in ABC-I score from baseline), and percentage of patients with CGI of Change (CGI-C) ratings of "much improved" and "very much improved" at OLE endpoint, were evaluated.

\section{Statistical methods}

There was no formal sample size calculation. All safety and efficacy analyses were summarized descriptively, into three groups based on the randomization group in the DB phase.

Placebo/risperidone group: Patients randomly assigned to placebo during the DB phase and who continued into the OLE and received risperidone

Risperidone low-dose/risperidone group: Patients randomly assigned to risperidone low dose during the DB phase and who continued into the OLE and received risperidone.

Risperidone high-dose/risperidone group: Patients randomly assigned to risperidone high dose during the DB phase and who continued into the OLE and received risperidone.

The baseline characteristics collected during the DB phase, before randomization, were summarized separately for patients who entered the OLE. For patients who dropped out before completing the OLE, the last non-missing, post-OLE-baseline observation was used as the OLE end-point.

ABC-I response at OLE end-point (defined as $\geq 25 \%$ improvement from DB baseline) and the percentage of patients with CGI-C ratings of "much improved" or "very much improved" were analyzed using $\chi^{2}$ tests.

All patients who received at least one dose of the study drug were included in the efficacy (open-label analysis set) and safety analyses (open-label safety analysis set).

\section{Results}

\section{Patient disposition and characteristics}

Of the 96 patients randomized in the DB phase, 79 (82\%) entered the OLE phase, and $56(71 \%)$ completed the study. The most common reasons for discontinuation were insufficient response $(n=7$ [9\%]), AEs $(n=5[6 \%])$, and being lost to follow-up ( $n=4$ [5\%]) (Fig. 1).

The majority of the study population was male $(89 \%)$. The mean (SD) age was 9 (3.1) years (range: 5-17 years), and $81 \%$ of the population were $<12$ years old. The mean (SD) age at first diagnosis of autism was 4 (2.6) years (range: 2-14 years) (Table 1).

The median mode dose administered during the OLE phase was $0.875 \mathrm{mg} /$ day $(0.125-1.25 \mathrm{mg} /$ day $)$ in the patients weighing 20 to $<45 \mathrm{~kg}$, and $1 \mathrm{mg} /$ day $(0.25-2.00 \mathrm{mg} / \mathrm{day}$; one patient received $2.00 \mathrm{mg} /$ day, which was a protocol deviation) in patients weighing $\geq 45 \mathrm{~kg}$. The median duration of treatment was 178 days, with 33 (42\%) patients treated for $\geq 6$ months (180-201 days). Twenty one $(70 \%)$ patients in placebo/risperidone group, 14 (58.3\%) patients in risperidone low-dose/risperidone group, and 16 (64\%) patients in risperidone high-dose/risperidone group received concomitant medications. The most commonly used (more than five patients) concomitant medications were, paracetamol $(n=9$ [11.4\%]), ibuprofen $(n=8[10.1 \%])$, amoxicillin $(n=7[8.9 \%])$ loratadine $(n=6[7.6 \%])$, and diphenhydramine hydrochloride $(n=5[6.3 \%])$.

\section{Safety}

A total of $50(63 \%)$ patients experienced AEs in the OLE phase. The most common AEs ( $>5 \%$ in total group) reported were increased appetite $(11 \%)$, increased weight $(9 \%)$, vomiting $(9 \%)$, sedation $(8 \%)$, pyrexia $(8 \%)$, upper respiratory tract infection $(8 \%)$, nasopharyngitis $(6 \%)$, somnolence $(5 \%)$, and fatigue $(5 \%)$ (Table 2$)$.

Table 1. Pretreatment Baseline Characteristics of Patients Entering Open-Label Extension Phase (Intent-to-Treat Analysis Set)

\begin{tabular}{|c|c|c|c|c|}
\hline Parameters & $\begin{array}{c}\text { Placebo/RIS }(\mathrm{n}=30) \\
\mathrm{n}(\%)\end{array}$ & $\begin{array}{c}\text { RIS low-dose/RIS }(\mathrm{n}=24) \\
\mathrm{n}(\%)\end{array}$ & $\begin{array}{c}\text { RIS high-dose/RIS }(\mathrm{n}=25) \\
\mathrm{n}(\%)\end{array}$ & $\begin{array}{c}\text { Total }(\mathrm{n}=79) \\
\mathrm{n}(\%)\end{array}$ \\
\hline \multicolumn{5}{|c|}{ Age (years) Category } \\
\hline $0-<12$ & $27(90)$ & $17(71)$ & $20(80)$ & $64(81)$ \\
\hline$>12$ & $3(10)$ & $7(29)$ & $5(20)$ & $15(19)$ \\
\hline Mean (SD) & $8.5(2.53)$ & $10(3.7)$ & $9.2(2.82)$ & $9.2(3.1)$ \\
\hline \multicolumn{5}{|l|}{ Sex } \\
\hline Boys & $26(87)$ & $21(88)$ & $23(92)$ & $70(89)$ \\
\hline Girls & $4(13)$ & $3(13)$ & $2(8)$ & $9(11)$ \\
\hline \multicolumn{5}{|l|}{ Race } \\
\hline White & $18(60)$ & $16(67)$ & $21(84)$ & $55(70)$ \\
\hline Black & $9(30)$ & $5(21)$ & $2(8)$ & $16(20)$ \\
\hline Asian & 0 & $1(4)$ & 0 & $1(1)$ \\
\hline Other & $1(3)$ & $1(4)$ & $2(8)$ & $4(5)$ \\
\hline \multicolumn{5}{|c|}{ Baseline body mass index $\left(\mathrm{kg} / \mathrm{m}^{2}\right)$} \\
\hline Mean (SD) & $19.5(4.87)$ & $20.4(5.64)$ & $18.7(4.74)$ & $19.5(5.05)$ \\
\hline \multicolumn{5}{|c|}{ Age at first diagnosis of autism } \\
\hline Mean (SD) & $4.7(2.75)$ & $5.0(3.07)$ & $3.8(1.89)$ & $4.5(2.63)$ \\
\hline \multicolumn{5}{|c|}{ Mental age (years) } \\
\hline Mean (SD) & $5.6(2.60)$ & $6.4(3.31)$ & $6.2(3.40)$ & $6.0(3.07)$ \\
\hline \multicolumn{5}{|c|}{ Previous antipsychotic use } \\
\hline Yes & $2(7)$ & $3(13)$ & $2(8)$ & $7(9)$ \\
\hline No & $28(93)$ & $21(88)$ & $23(92)$ & $72(91)$ \\
\hline
\end{tabular}

RIS, risperidone; placebo/RIS, patients randomly assigned to placebo during double-blind (DB) phase who continued into open-label extension (OLE) and received risperidone; RIS low dose/RIS, patients randomly assigned to risperidone low dose during DB phase who continued into OLE and received risperidone; RIS high dose/RIS, patients randomly assigned to risperidone high dose during DB phase who continued into OLE and received risperidone. 
Table 2. Overall Adverse Events (AEs) in Open-Label Extension Phase (Open-Label Safety Analysis Set)

\begin{tabular}{|c|c|c|c|c|}
\hline & $\begin{array}{c}\text { Placebo/RIS }(\mathrm{n}=30) \\
\mathrm{n}(\%)\end{array}$ & $\begin{array}{c}\text { RIS low-dose/RIS }(\mathrm{n}=24) \\
\mathrm{n}(\%)\end{array}$ & $\begin{array}{c}\text { RIS high-dose/RIS }(\mathrm{n}=25) \\
\mathrm{n}(\%)\end{array}$ & $\begin{array}{c}\text { Total }(\mathrm{n}=79) \\
\mathrm{n}(\%)\end{array}$ \\
\hline Total no. patients with AEs & $21(70)$ & $14(58)$ & $15(60)$ & $50(63)$ \\
\hline \multicolumn{5}{|c|}{ Treatment-Emergent Adverse Events in at least 2 patients in any group } \\
\hline Increased appetite & $7(23)$ & $2(8)$ & 0 & $9(11)$ \\
\hline Weight increased & $5(17)$ & $1(4)$ & $1(4)$ & $7(9)$ \\
\hline Vomiting & $2(7)$ & $3(13)$ & $2(8)$ & $7(9)$ \\
\hline Upper respiratory tract infection & $2(7)$ & $2(8)$ & $2(8)$ & $6(8)$ \\
\hline Pyrexia & $1(3)$ & $3(13)$ & $2(8)$ & $6(8)$ \\
\hline Sedation & $4(13)$ & $1(4)$ & $1(4)$ & $6(8)$ \\
\hline Nasopharyngitis & $2(7)$ & $1(4)$ & $2(8)$ & $5(6)$ \\
\hline Headache & $3(10)$ & 0 & $1(4)$ & $4(5)$ \\
\hline Cough & $2(7)$ & $1(4)$ & $1(4)$ & $4(5)$ \\
\hline Enuresis & $2(7)$ & $1(4)$ & $1(4)$ & $4(5)$ \\
\hline Diarrhea & $1(3)$ & $1(4)$ & $2(8)$ & $4(5)$ \\
\hline Fatigue & $2(7)$ & $1(4)$ & $1(4)$ & $4(5)$ \\
\hline Somnolence & $3(10)$ & 0 & $1(4)$ & $4(5)$ \\
\hline Influenza & $2(7)$ & $1(4)$ & 0 & $3(4)$ \\
\hline Agitation & $2(7)$ & 0 & $1(4)$ & $3(4)$ \\
\hline Insomnia & $1(3)$ & $2(8)$ & 0 & $3(4)$ \\
\hline Abdominal discomfort & $2(7)$ & 0 & 0 & $2(3)$ \\
\hline Sinusitis & $2(7)$ & 0 & 0 & $2(3)$ \\
\hline Oropharyngeal pain & 0 & 0 & $2(8)$ & $2(3)$ \\
\hline \multicolumn{5}{|c|}{ Extrapyramidal symptom-related treatment emergent events in all patients } \\
\hline Total no. patients with AEs & $2(7)$ & $2(8)$ & $2(8)$ & $6(8)$ \\
\hline Drooling & $1(3)$ & $1(4)$ & 0 & $2(3)$ \\
\hline Dyskinesia & 0 & $1(4)$ & 0 & $1(1)$ \\
\hline Tic & 0 & 0 & $1(4)$ & $1(1)$ \\
\hline Blepharospasm & $1(3)$ & 0 & 0 & $1(1)$ \\
\hline Psychomotor hyperactivity & 0 & 0 & $1(4)$ & 1 (1) \\
\hline
\end{tabular}

RIS, risperidone; placebo/RIS, patients randomly assigned to placebo during double-blind (DB) phase who continued into open-label extension (OLE) and received risperidone; RIS low dose/RIS, patients randomly assigned to risperidone low dose during DB phase who continued into OLE and received risperidone; RIS high dose/RIS, patients randomly assigned to risperidone high dose during DB phase who continued into OLE and received risperidone.

Three AEs, occurring in more than one patient per DB risperidone treatment group, first emerged in the DB treatment phase and continued into the OLE phase. These were: increased appetite (17\% of patients in the DB low dose risperidone group, $32 \%$ in the DB high dose group), weight increase (13\% of patients in the DB low dose group, $16 \%$ in the DB high dose group), and somnolence ( $0 \%$ of patients in the DB low dose group, $16 \%$ in the DB high dose group).

Investigators reported six AEs in the OLE as severe (based on the investigator's clinical judgment and their experience with other patients with this disorder): agitation and hydrocele $(n=1[4 \%]$ each) in the risperidone high-dose/risperidone group; aggression and insomnia ( $n=1[4 \%]$ each) in the risperidone low-dose/risperidone group; and migraine and foot fracture $(n=1$ [3\%] each) in the placebo/risperidone group.

Only one serious AE was reported during the OLE (hydrocele). This AE occurred in the risperidone high-dose/risperidone group and was considered by the investigator as not related to risperidone. The AE resolved after hydrocele hernia surgery, but was followed by a diagnosis of idiopathic thrombocytopenia purpura and a low platelet count of $14,000 / \mathrm{mm}^{3}$.

Five patients withdrew from the OLE because of AEs; four in the placebo/risperidone group and one in the risperidone high-dose/ risperidone group. One of these patients in the placebo/risperidone group experienced seven distinct AEs (blepharospasm, confused state, crying, decreased appetite, irritability, self-injurious behavior, and somnolence). One patient each had the AE of fatigue and weight increase. One patient experienced treatment-emergent markedly abnormal neutropenia (product label AE for risperidone) while receiving $1.25 \mathrm{mg} /$ day dose of risperidone. This patient recovered without sequela and without treatment after 3 days of discontinuation of risperidone. In the risperidone high-dose/risperidone group, one patient withdrew because of vomiting.

In the OLE phase, the frequency of somnolence- $(n=7$ [23\%]) and fatigue- $(n=2[7 \%])$ related AEs was highest in the placebo/ risperidone group. The frequency of EPS-related AEs was similar across all groups (two patients in each of the three groups) (Table 2).

Although no clinically relevant changes were observed from the DB baseline to the OLE end-point in any of the laboratory analytes (Table 3), there were slight elevations in several parameters related to metabolic safety. A mean increase in triglyceride levels was observed in the risperidone high-dose/risperidone group. Mean IGF-1 levels increased from DB baseline to OLE end-point in all treatment groups. Five (8\%) patients with IGF-1 SDS within \pm 2 at the DB baseline had an SDS value $<-2$ at the OLE end-point (Table 3). HOMA-IR values increased the most in the risperidone high dose/risperidone group (Table 3 ).

Mean increases from DB baseline to OLE end-point in prolactin levels were greater in the risperidone low-dose/risperidone $(13.74 \mathrm{ng} / \mathrm{mL})$ and high-dose/risperidone groups $(13.51 \mathrm{ng} / \mathrm{mL})$ than in the placebo/risperidone group $(12.36 \mathrm{ng} / \mathrm{mL})$ (Table 4$)$. One potentially prolactin-related AE (irregular menstruation) was reported during the study, and occurred in the risperidone lowdose/risperidone group. 
Table 3. Mean Change from Double-Blind Baseline to Open-Label End-Point in Clinical Laboratory Analytes and HOMA-IR Values (Open-Label Safety Analysis Set)

\begin{tabular}{|c|c|c|c|}
\hline Laboratory analytes & Placebo/RIS group $(\mathrm{n}=30)$ & RIS low-dose/RIS group $(\mathrm{n}=24)$ & RIS high-dose/RIS group $(\mathrm{n}=25)$ \\
\hline \multicolumn{4}{|l|}{ Glucose (mg/dL) } \\
\hline Mean baseline & $87.0(9.88)$ & $87.2(9.04)$ & $91.9(5.15)$ \\
\hline Mean change (SD) & $4.0(12.3)$ & $3.5(12.3)$ & $2.3(8.8)$ \\
\hline Median change (range) & $6.0(-20 ; 31)$ & $6.0(-27 ; 19)$ & $1.0(-13 ; 15)$ \\
\hline \multicolumn{4}{|l|}{ Insulin $(\mathrm{uU} / \mathrm{mL})$} \\
\hline Mean baseline & $9.2(16.28)$ & $5.3(3.72)$ & $4.93(2.40)$ \\
\hline Mean change (SD) & $-0.11(12.19)$ & $1.64(3.93)$ & $3.21(4.01)$ \\
\hline Median change (range) & $2.42(-48.2 ; 9.3)$ & $1.46(-4.60 ; 10.31)$ & $2.13(-1.72 ; 11.06)$ \\
\hline \multicolumn{4}{|l|}{ Lipids (mg/dL) } \\
\hline \multicolumn{4}{|l|}{ Cholesterol } \\
\hline Mean baseline & $163.7(24.23)$ & $153.4(33.33)$ & $165.9(21.36)$ \\
\hline Mean change (SD) & $2.5(25.08)$ & $0.3(21.4)$ & $-1.6(10.82)$ \\
\hline Median change (range) & $-1.0(-43 ; 60)$ & $-1.5(-49 ; 33)$ & $-3.5(-17 ; 21)$ \\
\hline \multicolumn{4}{|l|}{ LDL } \\
\hline Mean baseline & $94.1(25.61)$ & 85.7 (29.47) & $97.9(21.37)$ \\
\hline Mean change (SD) & $1.5(20.55)$ & $0.4(19.36)$ & $-0.6(10.94)$ \\
\hline Median change (range) & $-1.0(-32 ; 45)$ & $5.0(-59 ; 27)$ & $-1.0(-22 ; 26)$ \\
\hline \multicolumn{4}{|l|}{ HDL } \\
\hline Mean baseline & $53.9(13.80)$ & $55.4(8.62)$ & $54.9(10.48)$ \\
\hline Mean change (SD) & $-0.4(7.01)$ & $-1.9(9.14)$ & $-6.6(10.21)$ \\
\hline Median change (range) & $1.0(-13 ; 13)$ & $-1.0(-17 ; 16)$ & $-8.0(-25 ; 13)$ \\
\hline \multicolumn{4}{|l|}{ Triglycerides } \\
\hline Mean baseline & $78.2(42.57)$ & $61.9(20.88)$ & $66.1(30.77)$ \\
\hline Mean change (SD) & $7.2(40.86)$ & $0.0(22.05)$ & $20.3(34.65)$ \\
\hline Median change (range) & $4.0(-66 ; 117)$ & $4.5(-43 ; 46)$ & $11.0(-27 ; 107)$ \\
\hline \multicolumn{4}{|c|}{ Growth Hormones and Growth Factors } \\
\hline \multicolumn{4}{|c|}{ TSH (uU/mL) } \\
\hline Mean baseline & $1.69(0.55)$ & $1.89(0.82)$ & $2.16(1.04)$ \\
\hline Mean change (SD) & $0.09(0.816)$ & $0.27(0.914)$ & $0.05(0.926)$ \\
\hline Median change (range) & $0.0(-1.4 ; 2.1)$ & $0.2(-1.1 ; 2.4)$ & $0.1(-2.3 ; 2.5)$ \\
\hline \multicolumn{4}{|l|}{ Thyroxine $(\mu \mathrm{g} / \mathrm{dL})$} \\
\hline Mean baseline & $8.1(1.68)$ & $7.9(1.12)$ & $8.7(1.64)$ \\
\hline Mean change (SD) & $0.90(2.68)$ & $0.38(0.99)$ & $0.06(1.72)$ \\
\hline Median change (range) & $0.4(-2.6 ; 10.1)$ & $0.3(-1.2 ; 2.6)$ & $0.1(-2.5 ; 4.1)$ \\
\hline \multicolumn{4}{|l|}{ IGF-1 (ng/mL) } \\
\hline Mean baseline & $167.3(79.73)$ & $153.9(72.29)$ & $129.1(44.31)$ \\
\hline Mean change (SD) & $39.2(71.41)$ & $40.6(59.80)$ & $53.1(73.65)$ \\
\hline Median change (range) & $28.0(-108 ; 255)$ & $21.5(-47 ; 167)$ & $22.0(-29 ; 237)$ \\
\hline \multicolumn{4}{|l|}{ IGF-1 SDS } \\
\hline Mean baseline & $0.10(0.83)$ & $-0.65(1.26)$ & $-0.85(1.09)$ \\
\hline Mean change (SD) & $0.41(0.96)$ & $0.54(0.98)$ & $0.56(1.01)$ \\
\hline Median change (range) & $0.37(-0.98 ; 2.96)$ & $0.30(-1.17 ; 2.27)$ & $0.47(-1.61 ; 2.22)$ \\
\hline \multicolumn{4}{|l|}{ IGF-BP-3 (ng/mL) } \\
\hline Mean baseline & $3002.4(773.20)$ & $2709.1(629.30)$ & $2813.2(716.90)$ \\
\hline Mean change (SD) & $-231.7(707.34)$ & $-41.5(517.87)$ & $-159.1(715.06)$ \\
\hline Median change (range) & $-148.0(-1437 ; 933)$ & $-47.0(-1028 ; 1422)$ & $-93.0(-1257 ; 1400)$ \\
\hline \multicolumn{4}{|l|}{ HOMA-IR } \\
\hline Mean baseline & 2.03 & 1.26 & 1.11 \\
\hline Mean change (SD) & $0.09(2.67)$ & $0.36(0.89)$ & $0.75(0.91)$ \\
\hline
\end{tabular}

HDL, high density lipoprotein; LDL, low-density lipoprotein; TSH, thyroid-stimulating hormone; IGF, insulin growth factor; IGF-BP, insulin growth factor-binding protein; HOMA-IR, homeostatic model assessment of insulin resistance; RIS, Risperidone; placebo/RIS, patients randomly assigned to placebo during double-blind (DB) phase who continued into open-label extension (OLE) and received risperidone; RIS low dose/RIS, patients randomly assigned to risperidone low dose during DB phase who continued into OLE and received risperidone; RIS high dose/RIS, patients randomly assigned to risperidone high dose during DB phase who continued into OLE and received risperidone.

[HOMA-IR] formula: glucose $[\mathrm{mmol} / \mathrm{L}] \times$ insulin $[\mu \mathrm{U} / \mathrm{mL}] / 22.5$ (Wallace et al. 2004). 
Table 4. Mean Change in Prolactin Levels (Open-Label Safety Analysis Set)

\begin{tabular}{lcccc}
\hline & Baseline $($ OLE) & Week 13(OLE) & Week 26 (OLE) & End-point (OLE) \\
\hline $\begin{array}{l}\text { Treatment group } \\
\text { Placebo/RIS }\end{array}$ & & & & \\
$\quad$ Mean DB baseline & $8.98(5.63)$ & $8.64(4.83)$ & $8.03(3.67)$ & $8.64(4.83)$ \\
$\quad$ Mean change from DB Baseline (SD) & $0.05(5.21)$ & $17.08(12.13)$ & $11.47(8.02)$ & $12.36(11.58)$ \\
RIS low dose/RIS & & & \\
$\quad$ Mean DB baseline & $9.46(5.96)$ & $8.44(5.72)$ & $8.53(6.08)$ & $8.44(5.72)$ \\
$\quad$ Mean change from DB Baseline (SD) & $3.14(5.62)$ & $12.71(14.36)$ & $15.67(13.05)$ & $13.74(13.49)$ \\
RIS high dose/RIS & & & \\
$\quad \begin{array}{l}\text { Mean DB baseline } \\
\text { Mean change from DB Baseline (SD) }\end{array}$ & $9.87(10.13)$ & $7.35(3.36)$ & $7.42(3.62)$ & $7.35(3.36)$ \\
\hline
\end{tabular}

RIS, risperidone; placebo/RIS, patients randomly assigned to placebo during double-blind (DB) phase who continued into open-label extension (OLE) and received risperidone; RIS low dose/RIS, patients randomly assigned to risperidone low dose during DB phase who continued into OLE and received risperidone; RIS high dose/RIS, patients randomly assigned to risperidone high dose during DB phase who continued into OLE and received risperidone.

Mean weight $(\mathrm{kg})$ and body mass index (BMI) $\left(\mathrm{kg} / \mathrm{m}^{2}\right)$ increased in all groups during OLE (increases in weight ranged from $11 \%$ to $15 \%$; increases in BMI ranged from $5 \%$ to $10 \%$ ) (Table 5). The weight and the BMI $Z$-scores plateaued at 3-6 months in the risperidone high-dose/risperidone group (Fig. 2).

The quality of sleep VAS scores improved the most in the risperidone high-dose/risperidone group (mean baseline, 60.4; mean [SD] increase, 24.6 [31.6]), and were comparable between the risperidone low-dose/risperidone- (mean baseline, 70.3; mean [SD] increase, 9.8 [32.5]) and the placebo/risperidone groups (mean baseline, 70; mean [SD] increase, 14.5 [30.1]). Mean daytime drowsiness VAS score did not change in any treatment group at OLE end-point (risperidone high-dose/risperidone group: mean baseline, 19.5; mean [SD] decrease, -2 [27.11]; risperidone lowdose/risperidone group: mean baseline, 20.2; mean [SD] decrease, -2.6 [27.21]; and placebo/risperidone group: mean baseline, 18.3; mean [SD] decrease, -2.4 [22.89]). There was minimal to no change in any group in EPS rating scale scores. Of the 46 patients who had Tanner stage assessments at DB baseline and OLE endpoint, $39(85 \%)$ remained in the same Tanner stage, and $7(15 \%)$ patients had an increase of one Tanner stage.

No clinically significant change was seen in the vital signs and physical examination findings in any treatment groups.

\section{Efficacy}

The improvement in ABC-I subscale scores observed in the DB phase continued in the OLE for all treatment groups (Fig. 3). The ABC-I response rate improved from $41 \%$ (14/34) at DB end-point to $76 \%(22 / 29)$ at OLE end-point in the placebo/risperidone group, and from $52 \%(15 / 29)$ at DB end-point to $79 \%(19 / 24)$ at OLE endpoint in low-dose risperidone/risperidone group, whereas for risperidone high-dose/risperidone group the improvement in response rate observed at DB end-point (83\% [24/29]) was maintained at OLE end-point (83\% [20/24]). The percentage of patients with ABC-I response at OLE endpoint (defined as $\geq 25 \%$ improvement from $\mathrm{DB}$ baseline) was not statistically significantly different among the three groups $(p=0.800)$. The other ABC-subscales scores, CGI-S, and CY-BOCS-PDD compulsion scale scores also improved (decreased) from DB baseline to OLE end-point across all the groups (Table 6).

The percentage of patients showing "much" or "very much" improvement in the CGI-C scores was numerically higher in the placebo/risperidone group $(69 \%, 20 / 29)$, than in either the risperidone high-dose/risperidone, $(60 \%, 15 / 25)$ or low-dose/risperidone $(58 \%$, $14 / 24)$ groups. This was expected, as this group of patients was switched from placebo to active (risperidone) treatment and change

Table 5. Mean Change from Double-Blind Baseline to Open-Label End-Point in Weight and Body Mass Index (Open-Label Safety Analysis Set)

\begin{tabular}{|c|c|c|c|}
\hline & Placebo/RIS group $(\mathrm{n}=30)$ & RIS low-dose/RIS group $(\mathrm{n}=24)$ & RIS high-dose/RIS group $(\mathrm{n}=25)$ \\
\hline \multicolumn{4}{|l|}{ Weight $(\mathrm{kg})$} \\
\hline Mean (SD) baseline & $37.9(18.00)$ & $40.3(24.76)$ & $36.5(15.86)$ \\
\hline Mean change (SD) & $4.3(3.25)$ & $4.7(3.72)$ & $5.5(2.86)$ \\
\hline \multicolumn{4}{|l|}{ Weight $Z$ score } \\
\hline Mean (SD) baseline & $0.90(1.20)$ & $0.43(1.43)$ & $0.34(1.27)$ \\
\hline Mean change (SD) & $0.22(0.330)$ & $0.36(0.410)$ & $0.40(0.340)$ \\
\hline \multicolumn{4}{|l|}{$\operatorname{BMI}\left(\mathrm{kg} / \mathrm{m}^{2}\right)$} \\
\hline Mean (SD)baseline & $19.5(4.96)$ & $20.1(5.82)$ & $18.8(4.85)$ \\
\hline Mean change (SD) & $1.1(1.30)$ & $1.5(1.76)$ & $2.0(1.67)$ \\
\hline \multicolumn{4}{|l|}{ BMI $Z$ score } \\
\hline Mean baseline & $0.75(1.32)$ & $0.78(1.20)$ & $0.26(2.11)$ \\
\hline Mean change (SD) & $0.27(0.424)$ & $0.25(0.473)$ & $0.69(1.643)$ \\
\hline
\end{tabular}

BMI, body mass index; RIS, risperidone; placebo/RIS, patients randomly assigned to placebo during double-blind (DB) phase who continued into open-label extension (OLE) and received risperidone; RIS low dose/RIS, patients randomly assigned to risperidone low dose during DB phase who continued into OLE and received risperidone; RIS high dose/RIS, patients randomly assigned to risperidone high dose during DB phase who continued into OLE and received risperidone. 

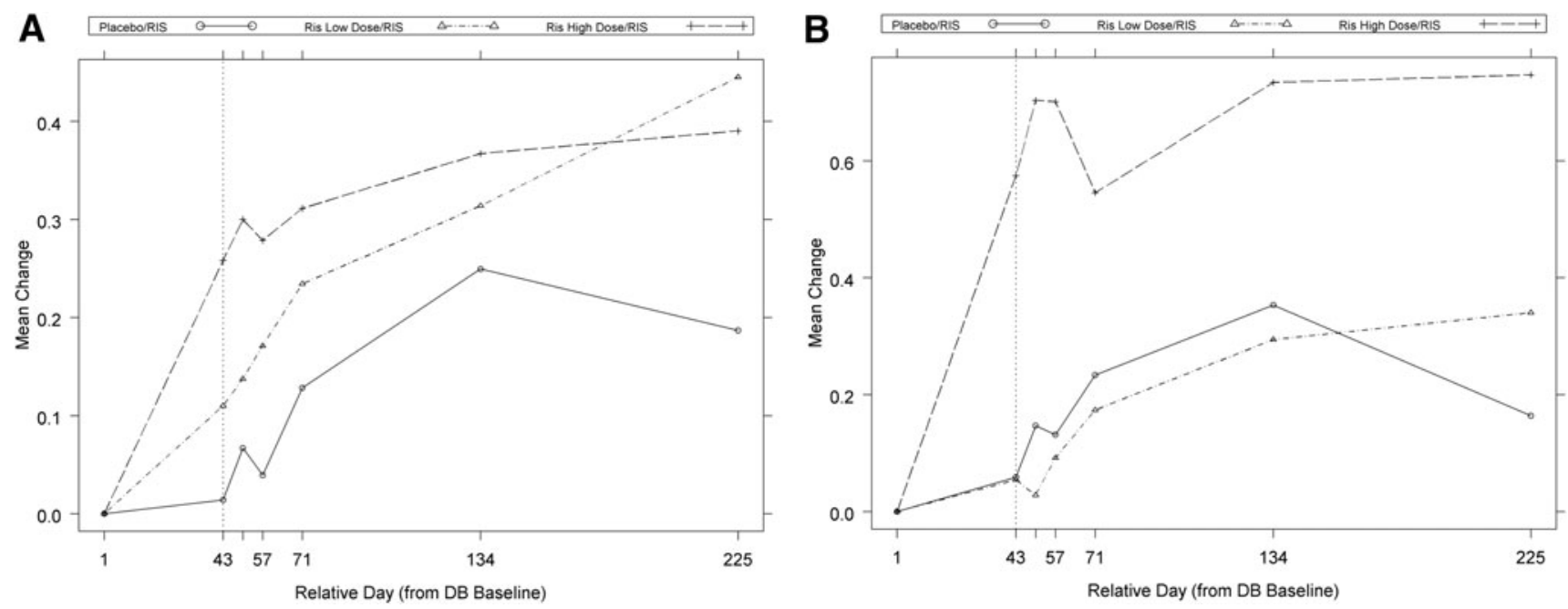

FIG. 2. Mean change in weight and body mass index (BMI) Z-scores over time (open-label safety analysis set). (A) Mean change in weight. (B) Mean change in BMI Z-scores. RIS, risperidone; placebo/RIS, patients randomly assigned to placebo during double-blind (DB) phase who continued into open-label extension (OLE) and received risperidone; RIS low dose/RIS, patients randomly assigned to risperidone low dose during DB phase who continued into OLE and received risperidone; RIS high dose/RIS, patients randomly assigned to risperidone high dose during DB phase who continued into OLE and received risperidone.

was measured from the start of the open-label trial; however, patients who continued on risperidone also showed additional clinical improvement. The percentage of patients with CGI-C ratings of "much" or "very much" improvement at OLE endpoint was not statistically significantly different among the three groups $(p=0.684)$.

\section{Discussion}

As antipsychotic drugs are frequently used long term in treating patients with autism, determining the lowest effective dose for these drugs is important from a safety perspective. This 26 week

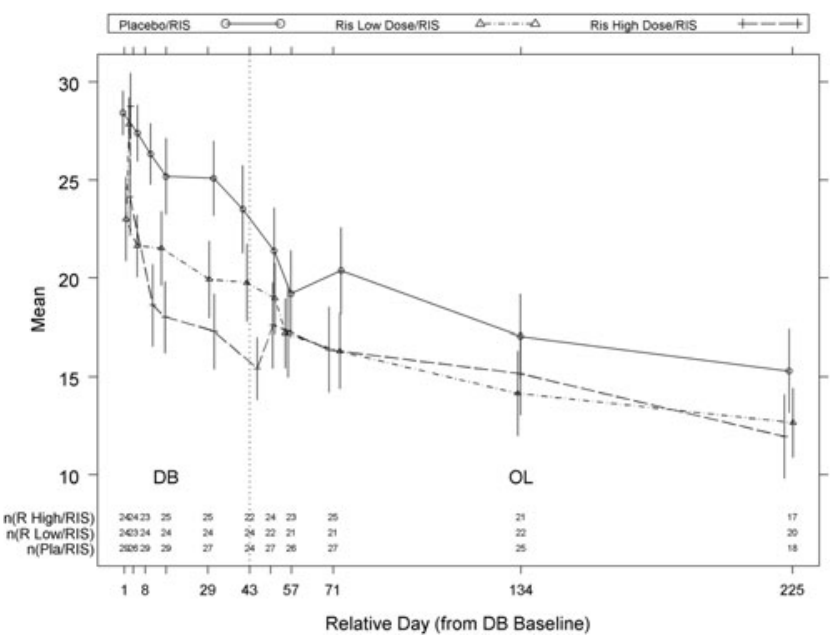

FIG. 3. Mean ( \pm standard error [SE]) Aberrant Behavior Checklist Irritability Subscale over time (open label analysis set). Placebo/RIS, patients randomly assigned to placebo during double-blind (DB) phase who continued into open-label extension (OLE) and received risperidone; RIS low dose/RIS, patients randomly assigned to risperidone low dose during DB phase who continued into OLE and received risperidone; RIS high dose/RIS, patients randomly assigned to risperidone high dose during DB phase who continued into OLE and received risperidone.
OLE followed a 6 week DB phase that assessed the efficacy and safety of risperidone at two fixed, weight-based dose ranges (low dose $=0.125$ or $0.175 \mathrm{mg} /$ day and high dose $=1.25$ or $1.75 \mathrm{mg} /$ day , compared with placebo, in patients with autism. The low dose regimen selected was much lower than the currently recommended dose of risperidone ( $1 \mathrm{mg} /$ day for patients weighing $>20 \mathrm{~kg}$ ), and was based on the recommendation of the United States Food and Drug Administration. In the OLE phase of the study, patients were flexibly dosed up to a maximum dose of 1.25 and $1.75 \mathrm{mg}$ /day (median mode dose, 0.875 or $1 \mathrm{mg} /$ day).

Risperidone exhibited a safety profile consistent with the previously reported safety information that was based on a dose range of $0.5-3 \mathrm{mg} / \mathrm{day}$ in patients with autism and other disruptive behavior disorders (Malone et al 2002; Masi et al 2003; Martin et al 2004; Research Units on Pediatric Psychopharmacology 2005; Troost et al. 2005; Aman et al 2009). The most common ( $\geq 5 \%)$ AEs were increased appetite, increased weight, vomiting, sedation, pyrexia, upper respiratory tract infection, nasopharyngitis, somnolence, and fatigue; none of these events were rated as severe. Hydrocele was the only serious AE reported during the OLE, and was considered to be unrelated to risperidone. There were few discontinuations during the OLE study, and most of these discontinuations were in patients who were previously (during the DB phase) treated with placebo and then received risperidone during the OLE, as may be expected, because of the difference in adverse event profiles between placebo and active compounds. The fact that two thirds of the patients eligible for the OLE had previous exposure to risperidone during the $\mathrm{DB}$ phase, whereas one third, assigned to placebo during the DB phase, had no previous exposure to risperidone, introduced some heterogeneity into the OLE sample. This fact biases the sample somewhat, in that only those patients in the placebo arm and those who tolerated risperidone in the DB phase continued into the OLE. Those patients who did not tolerate risperidone in the DB phase were not included in the OLE phase, and, therefore, their data are not represented here, which is a shortcoming of this study design.

Somnolence (Turgay et al. 2002; Shea et al. 2004; Pandina et al. 2007) and EPS-related events (Turgay et al. 2002; Haas et al. 2009) 
Table 6. Mean Change from Double-Blind Baseline to Open-Label End-Point in Clinical

Global Impressions-Severity Scale, Children's Yale-Brown Obsessive Compulsive Scale, and Aberrant Behavior Checklist Subscales (Open-Label Analysis Set)

\begin{tabular}{|c|c|c|c|}
\hline & $\begin{array}{l}\text { Placebo/RIS } \\
\text { group }(\mathrm{n}=30)\end{array}$ & $\begin{array}{l}\text { RIS low-dose/RIS } \\
\text { group }(\mathrm{n}=24)\end{array}$ & $\begin{array}{l}\text { RIS high-dose/RIS } \\
\text { group }(\mathrm{n}=25)\end{array}$ \\
\hline \multicolumn{4}{|c|}{ Clinical Global Impressions-Severity } \\
\hline Mean (SD) baseline & $4.9(0.67)$ & $5.1(0.93)$ & $5.0(0.75)$ \\
\hline Mean change (SD) & $-0.9(0.88)$ & $-1.0(1.02)$ & $-1.3(1.17)$ \\
\hline \multicolumn{4}{|l|}{ Compulsions total score } \\
\hline Mean (SD) baseline & $13.7(2.66)$ & $13.4(3.99)$ & $14.4(4.64)$ \\
\hline Mean change (SD) & $-5.3(4.99)$ & $-4.1(3.01)$ & $-5.6(4.66)$ \\
\hline \multicolumn{4}{|c|}{ Aberrant Behavior Checklist Subscales } \\
\hline \multicolumn{4}{|c|}{ Irritability } \\
\hline Mean (SD) baseline & $28.4(6.03)$ & $27.8(6.58)$ & $28.8(8.24)$ \\
\hline Mean change (SD) & $-11.8(7.68)$ & $-13.2(9.29)$ & $-13.0(10.55)$ \\
\hline \multicolumn{4}{|c|}{ Lethargy/social withdrawal } \\
\hline Mean (SD) baseline & $18.1(10.16)$ & $18.2(9.71)$ & $21.4(9.09)$ \\
\hline Mean change (SD) & $-6.9(8.08)$ & $-8.3(9.03)$ & $-10.4(8.57)$ \\
\hline \multicolumn{4}{|l|}{ Stereotyped behavior } \\
\hline Mean (SD) baseline & $10.5(5.26)$ & $9.3(5.17)$ & $11.5(5.06)$ \\
\hline Mean change (SD) & $-2.8(4.12)$ & $-4.2(6.51)$ & $-4.6(5.14)$ \\
\hline \multicolumn{4}{|l|}{ Hyperactivity } \\
\hline Mean (SD) baseline & $31.4(8.60)$ & $30.1(11.46)$ & $33.8(9.75)$ \\
\hline Mean change (SD) & $-11.7(8.54)$ & $-10.5(12.42)$ & $-12.3(11.78)$ \\
\hline \multicolumn{4}{|l|}{ Inappropriate speech } \\
\hline Mean (SD) baseline & $5.9(3.42)$ & $6.6(3.49)$ & $7.5(2.78)$ \\
\hline Mean change (SD) & $-1.5(2.69)$ & $-1.8(3.93)$ & $-2.1(3.07)$ \\
\hline
\end{tabular}

RIS, risperidone; placebo/RIS, patients randomly assigned to placebo during double-blind (DB) phase who continued into open-label extension (OLE) and received risperidone; RIS low dose/RIS, patients randomly assigned to risperidone low dose during DB phase who continued into OLE and received risperidone; RIS high dose/RIS, patients randomly assigned to risperidone high dose during DB phase who continued into OLE and received risperidone.

were the events with the highest incidence observed with risperidone in the previous studies (dose range: $0.5-3 \mathrm{mg}$ for autism and disruptive behavior disorders; $1.5-6 \mathrm{mg}$ /day for schizophrenia). Contrary to these earlier studies, in this OLE, very few incidences of somnolence or EPS-related AEs were observed. Patients previously exposed to risperidone during the DB phase had a lower rate of somnolence than patients exposed to placebo. One patient from the placebo/risperidone group discontinued because of somnolence during the OLE phase. There was no worsening in the frequency of EPS-related AEs from the DB to the OLE phase. The EPS-related AEs of dyskinesia and blepharospasm were observed only during the OLE. One patient discontinued because of blepharospasm from the placebo/risperidone group. There was minimal to no change in EPS rating scale scores. There were no reports of tardive dyskinesia during either the OLE or the DB phase (Kent et al. 2013).

Consistent with the findings in DB phase (Kent et al. 2013), risperidone treatment also resulted in improvement in nighttime sleep quality during the OLE. However, there was essentially no change in daytime drowsiness VAS score in any treatment group at OLE end-point.

Risperidone treatment is associated with incidences of hyperglycemia, diabetes mellitus, and exacerbation of pre-existing diabetes mellitus (Risperdal ${ }^{\circledR}$ 2011). Assessment of the relationship between atypical antipsychotic use and glucose abnormalities is complicated by the increasing incidence of diabetes mellitus in the general population, and is correlated with weight gain. Given these confounding factors, the relationship between atypical antipsychotic use and hyperglycemia-related AEs is not completely understood. Contrary to certain findings from some other studies and the warning in the product labeling (Risperdal ${ }^{\circledR} 2011$ ), in this study no clinically meaningful increases occurred in mean fasting glucose, cholesterol, or low-density lipoprotein (LDL) levels with risperidone treatment; however, slight increases in triglycerides were noted in the risperidone high-dose/risperidone treatment group. The minimal changes observed in these metabolic parameters could be attributed to the relatively low doses of risperidone used in this study, compared with the recommended doses (effective dose range: 0.5-3 mg/day) for the treatment of patients with autism. Consistent with the known safety profile (Risperdal ${ }^{\circledR} 2011$ ), risperidone treatment was associated with glucose metabolism-related AEs of increased appetite and weight increase. The frequency of these AEs was highest in patients who had previously been administered placebo in the DB phase. It should be noted that the differential time of exposure may have affected AE reporting in this study.

Weight gain is one of the major issues associated with use of antipsychotic drugs in patients of all age groups. In both children and adolescents, age-inappropriate weight gain during development is a particularly important medical concern, as it could predict adult obesity, metabolic syndrome, cardiovascular morbidity, and malignancy (Correll 2008; Correll et al. 2009; Maayan and Correll 2011). In this OLE of approximately 6 months' duration, a mean increase of $4.3-5.5 \mathrm{~kg}$ in body weight was reported; only one patient discontinued because of weight increase. However, interpretation of increased weight is complicated in children and adolescents because of the increases expected as a function of normal growth and development, particularly over longer periods of time as in this 6 month OLE. Nonetheless, as atypical antipsychotics are associated with weight gain, psychoeducation, and instituting a dietary regimen and plan of physical activity may help in preventing or diminishing the weight gain associated with risperidone treatment 
(Turgay et al. 2002). It is also especially important to treat patients with the lowest effective dose, to decrease the potential for those AEs that may be dose-related.

Among the reported AEs in the OLE, increased appetite, increased weight, somnolence, and sedation occurred more frequently in the placebo/risperidone group than in the risperidone low-dose/risperidone or risperidone high-dose/risperidone groups. This suggests that treatment-associated AEs may emerge more commonly early in treatment.

Hyperprolactinemia is commonly observed with treatment of all D2 receptor antagonists, including risperidone (Alfaro et al. 2002; Anderson et al. 2007), and in some cases may be associated with potentially prolactin-related adverse events. Earlier studies show a trend in the prolactin profile with risperidone use at the recommended doses for autism: prolactin levels generally increase within 1-2 months of risperidone treatment initiation, after which levels often return within or close to normal by 3-5 months (Ali and Khemka 2008). A similar trend was generally observed in the current study, in which prolactin levels increased across all groups from DB baseline to OLE end-point. Patients treated with risperidone high dose in the DB phase showed a peak increase in prolactin levels at the end of the 6 week DB phase (OLE baseline). For the other two groups, a maximum increase in prolactin levels was observed within 13 weeks (first assessment) after initiation of risperidone treatment ( 1.25 or $1.75 \mathrm{mg} /$ day) in the OLE phase. Across groups, the prolactin levels then decreased but did not return within the baseline range by study end ( 26 weeks), and appeared to plateau. Only one patient had a potentially prolactin-related AE (no patient had a treatment-emergent markedly abnormal [>100 ng/ $\mathrm{mL}$ ] prolactin value).

Mean IGF-1 levels increased from DB baseline to OLE end-point, consistent with the findings observed in children and adolescents with conduct and other disruptive behavior disorders (Mills et al. 2007). There were no clear treatment-related changes in mean IGFBP-3 values. There were no clear treatment-related changes in thyroi-stimulating hormone or thyroxin throughout the study.

As was expected, sexual maturity, as assessed by Tanner staging, did not change for the majority of patients from DB baseline to OLE end-point. In the rest of the patients, Tanner stage increased by one. Small changes in height $Z$-scores indicated that the growth of children and adolescents continued on the same trajectory, with patients maintaining the same height percentile over the course of the study.

The efficacy scales scores during the OLE showed maintenance of efficacy, or some additional improvement from the DB study.

\section{Conclusions}

Risperidone, administered orally up to a maximum dose of $1.25 \mathrm{mg} /$ day for patients weighing 20 to $<45 \mathrm{~kg}$ (median mode dose $=0.875 \mathrm{mg} /$ day) or $1.75 \mathrm{mg} /$ day for patients weighing $\geq 45 \mathrm{~kg}$ (median mode dose $=1 \mathrm{mg} /$ day) in patients with autism ages 5-17 years for 26 weeks, had a safety profile consistent with the current safety information for risperidone, and with that established in previous studies with risperidone in patients with autistic disorder and other disruptive behavior disorders. Clinical benefit from treatment either continued with open-label treatment or showed additional improvement, and was consistent with previous studies.

\section{Clinical Significance}

Long-term safety issues are a major concern associated with antipsychotic drugs used in treatment of autism. Risperidone is one of the widely recommended drugs for treatment of irritability as- sociated with autistic disorder. The safety of risperidone in children and adolescents with autistic disorder was assessed in this study over a 26 week period. Increased appetite was the most common adverse event reported with risperidone treatment in this study. The safety profile was as expected and consistent with earlier reports.

\section{Acknowledgments}

Dr. Joseph Palumbo (Janssen Research \& Development, LLC) contributed to study design and manuscript review, Dr. Vivek Kusamakar (in memoriam) contributed importantly to the study, and Ms. Andrea Davis (Janssen Research \& Development, LLC) was the clinical trial manager. Dr. Ananya Chikramane (SIRO Clinpharm Pvt. Ltd.) provided writing assistance and Dr. Wendy P. Battisti (Janssen Research \& Development, LLC) contributed editorial support.

\section{Disclosures}

Drs. Singh, Hough, Kent, and Pandina, and Mr. Karcher are employees of Janssen Research \& Development, LLC and hold stock in the company. All authors had access to the study data and made the final decision about where to publish these data, and approved submission to the journal.

Drs. Kent and Singh participated in study governance and monitoring of data quality. Drs. Kent, Hough, and Singh participated in supervising study recruitment. Drs. Kent and Pandina, and Mr. Karcher participated in data analysis. Dr. Singh supervised study recruitment. Drs. Singh and Pandina, and Mr. Karcher participated in study design. All the authors participated in preparation of the first and the subsequent drafts of the manuscript.

\section{References}

Alfaro CL, Wudarsky M, Nicolson R, Gochman P, Sporn A, Lenane M, Rapoport JL: Correlation of antipsychotic and prolactin concentrations in children and adolescents acutely treated with haloperidol, clozapine, or olanzapine. J Child Adolesc Psychopharmacol 12:83-91, 2002.

Ali J, Khemka M: Hyperprolactinemia: Monitoring children on longterm risperidone. Current Psychiatry 7:64-72, 2008.

Aman MG, McDougle CJ, Scahill L, Handen B, Arnold LE, Johnson C, Stigler K, Bearss K, Butter E, Swiezy NB, Sukhodolsky DD, Ramadan Y, Pozdol SL, Nikolov R, Lecavalier L, Kohn AE, Koenig K, Hollway JA, Korzekwa P, Gavaletz A, Mulick JA, Hall KL, Dziura J, Ritz L, Trollinger S, Yu S, Vitiello B, Wagner A, RUPP: Medication and parent training in children with pervasive develomental disorders and serious behaviour problem: results from a randomised clinical trial. J Am Acad Child Adolesc Psychiatry 48:1143-1154, 2009.

American Psychiatric Association: Diagnostic and Statistical Manual of Mental Disorders, 4th ed. Washington, DC: American Psychiatric Association; 1994.

Anderson GM, Scahill L, McCracken JT, McDougle JC, Aman MG, Tierney E, Arnold LE, Martin A, Katsovich L, Posey D, Shah B, Vitiello B: Effect of short-and long-term risperidone treatment on prolactin levels in childern with autism. Biol Psychiatry 61:545-550, 2007.

Barnes TR: A rating scale for drug-induced akathisia. Br J Psychiatry 154:672-676, 1989.

Correll CU: Antipsychotic use in childern and adolescents: Minimizing adverse effects to maximize outcomes. J Am Acad Child Adolesc Psychiatry 47:1, 2008.

Correll CU, Manu P, Olshanskiy V, Barbara N, Kane JM, Malhotra AK: Cardiometabolic risk of second generation antipsychotics during first-time use in childern and adolescents. JAMA 302: 17651773, 2009. 
Elmlinger MW, Kuhnel W, Weber MM, Ranke MB: Reference ranges for two automated chemiluminescent assays for serum insulin-like growth factor I (IGF-I) and IGF-binding protein 3 (IGFBP-3). Clin Chem Lab Med 42:654-664, 2004.

Gagliano A, Germano E, Pustorino G, Impallomeni C, D’Arrigo C, Calamoneri F, Spina E: Risperidone treatment of children with autistic disorder: Effectiveness, tolerability, and pharmacokinetic implications. J Child Adolesc Psychopharmacol 14:39-47, 2004.

Guy W: ECDEU Assessment Manual for Psychopharmacology, revised. U.S. Department of Health, Education, and Welfare publication (ADM) 76-338. Rockville, MD: National Institute of Mental Health; 1976.

Haas M, Eerdekens M, Kushner S, Singer J, Augustyns I, Quiroz J, Pandina G, Kusumakar V: Efficacy, safety and tolerability of two dosing regimens in adolescent schizophrenia: double-blind study. Br J Psychiatry 194:158-164, 2009.

Harvey AG, Schmidt DA, Scarna A, Semler CN, Goodwin GM: Sleep-related functioning in euthymic patients with bipolar disorder, patients with insomnia, and subjects without sleep problems. Am J Psychiatry 162:50-57, 2005.

Kent JM, Kushner S, Ning X, Karcher K, Ness S, Aman M, Singh J, Hough D: Risperidone dosing in children and adolescents with autistic disorder: A double-blind, placebo-controlled study. J Autism Dev Disorder 43:1773-1783, 2013.

Maayan L, Correll CU: Weight gain and metabolic risk associated with antipsychotics medications in childern and adolescents. J Child Adolesc Psychopharmacol 21:517-535, 2011.

Marshall WA, Tanner JM: Variations in pattern of pubertal changes in girls. Arch Dis Child 44:291-303, 1969.

Marshall WA, Tanner JM: Variations in the pattern of pubertal changes in boys. Arch Dis Child 45:13-23, 1970.

Malone RP, Maislin G, Choudhury MA, Gifford C, Delaney MA: Risperidone treatment in children and adolescents with autism: short- and long-term safety and effectiveness. J Am Acad Child Adolesc Psychiatry 41:140-147, 2002.

Martin A, Scahill L, Anderson GM, Aman M, Arnold LE, McCracken J, McDougle CJ, Tierney E, Chuang S, Vitiello B, The Research Units of Pediatric psychopharmacology Autism Network: Weight and leptin changes among risperiodne-treated youths with autism: 6-month prospective data. Am J Psychiatry 161:1125-1127, 2004.

Masi G, Cosenza A, Mucci M, Brovedani P: A 3-year naturalistic study of 53 preschool children with pervasive developmental disorder treated with risperdione. J Clin Psychiatry 64:1039-1047, 2003.

Miles JH, McCathren RB, Stichter J, Marwan S: Autism Spectrum Disorder. Gene Reviews, 2010. Accessed 27 November 2012 at http://www.ncbi.nlm.nih.gov/books/NBK1442/

Mills JL, Hediger ML, Molloy CA, Chrousos GP, Manning-Courtney $\mathrm{P}, \mathrm{Yu} \mathrm{KF}$, Brasington M, England LJ: Elevated levels of growthrelated hormones in autism and autism spectrum disorder. Clin Endocrinol (Oxf) 67:230-237, 2007.

Nicolson R, Awad G, Sloman L: An open trial of risperidone in young autistic children. J Am Acad Child Adolesc Psychiatry 37:372-376, 1998.

Pandina GJ, Bossie CA, Youssef E, Zhu Y, Dunbar F: Risperidone improves behavioral symptoms in children with autism in a ran- domized, double-blind, placebo-controlled trial. J Autism Dev Disord 37:367-373, 2007.

Posey DJ, Stigler KA, Erickson CA, McDougle CJ: Antipsychotics in the treatment of autism. J Clin Invest 118:6-14, 2008.

Research Units on Pediatric Psychopharmacology Autism Network: Risperidone in children with autism and serious behavioral problems. N Engl J Med 347:314-321, 2002.

Research Units on Pediatric Psychopharmacology Autism Network: Risperidone treatment of autistic disorder: Longer-term benefits and blinded discontinuation after 6 months. Am J Psychiatry 162:13611369, 2005.

Risperdal ${ }^{\circledR}$, Prescribing information, Ortho-McNeil-Janssen Pharmaceuticals, Inc., 2011. Accessed 20 November 2013 at http://www .risperdal.com/sites/default/files/shared/pi/risperdal.pdf, 2002.

Scahill L, McDougle CJ, Williams SK, Dimitropoulos A,, Aman MG, McCracken JT, Tierney E, Arnold LE, Cronin P, Grados M, Ghuman J, Koenig K, Lam KS, McGough J, Posey DJ, Ritz L, Swiezy NB, Vitiello B, Research Units on Pediatric Psychopharmacology Autism Network: Children's Yale-Brown Obsessive Compulsive Scale Modified for Pervasive Developmental Disorders. J Am Acad Child Adolesc Psychiatry 45:1114-1123, 2006.

Lindgren S, Doobay A: Evidence-Based Interventions for Autism Spectrum Disorder, 2011. Accessed 27 November 2012 at http://www .healthcare.uiowa.edu/cdd/ucedd/research/files/impactdata/dhs $\% 20$ autism\%20interventions\%206-10-11.pdf

Shea S, Turgay A, Carroll A, Schulz M, Orlik H, Smith I, Dunbar F: Risperidone in the treatment of disruptive behavioral symptoms in children with autistic and other pervasive developmental disorders. Pediatrics 114:e634-641, 2004.

Simpson GM, Angus JW: A rating scale for extrapyramidal side effects. Acta Psychiatr Scand Suppl 212:11-19, 1970.

Troost PW, Lahuis BE, Steenhuis MP, Ketelaars CEJ, Buitelaar JK, Engeland HV, Scahill L, Minderaa RB, Hoekstra PJ: Long-term effects of risperidone in childern with autism spectrum disorders: A placebo discontinuation study. J Am Acad Child Adolesc Pschiatry 44:1137-1144, 2005.

Turgay A, Binder C, Snyder R, Fisman S: Long-term safety and efficacy of risperidone for the treatment of disruptive behavior disorders in children with subaverage IQs. Pediatrics 110:e34, 2002.

Wallace TM, Levy JC, Matthews DR: Use and abuse of HOMA modeling. Diabetes Care 27:1487-1495, 2004.

Williams SK, Scahill L, Vitiello B, Aman MG, Arnold LE, McDougle CJ, McCracken JT, Tierney E, Ritz L, Posey DJ, Swiezy NB, Hollway J, Cronin P, Ghuman J, Wheeler C, Cicchetti D, Sparrow S: Risperidone and adaptive behavior in children with autism. J Am Acad Child Adolesc Psychiatry 45:431-439, 2006.

Address correspondence to: Justine M. Kent, MD Janssen Research \& Development, LLC 1125 Trenton-Harbourton Road PO Box 200 Titusville, NJ 08560

E-mail: jkent@its.jnj.com 